\title{
The effect of rectal examination on serum acid phosphatase levels in benign and malignant prostatic disease
}

\author{
D. N. OSEGBE \\ F.R.C.S.(Ed.), F.M.C.S.(Nig.) \\ G. MAGOHA \\ M.B., B.S.(Lagos) \\ Urology Unit, Department of Surgery, \\ Lagos University Teaching Hospital, P.M.B. 12003, Lagos, Nigeria
}

\begin{abstract}
Summary
Serum acid phosphatase was measured in patients with enlarged benign and malignant prostate before and after rectal examination. Amongst the patients with benign glands, rectal examination did not produce any significant false elevation of the enzyme. Rectal examination, however, caused a rise in the enzyme level in a few untreated cancer patients and in cancer patients who had become refractory to hormonal therapy. This rise would help rather than mislead in the diagnosis of malignant prostate and also in identifying treated patients who had become refractory to treatment. Thus, when serum acid phosphatase is properly determined, elevated levels should always arouse suspicion of malignant prostate or other lesions associated with high enzyme level even if such determination was preceded by rectal examination.
\end{abstract}

There appears to be no merit in the teaching that the determination of serum acid phosphatase should be delayed after rectal examination.

\section{Introduction}

Prostatic acid phosphatase was first described by Kutscher and Wolbergs in 1935. Three years later Gutman and Gutman (1938) found that this enzyme was elevated in metastatic carcinoma of the prostate. The promise of this enzyme becoming a biological marker for the detection of carcinoma of the prostate was never fully realized. It soon became clear that serum acid phosphatase remained normal in $20 \%$ of cases of metastatic carcinoma of the prostate (Kendal, 1961). In early lesions, the enzyme remained normal in 95\% of cases (Woodward, 1952). The diagnostic value of acid phosphatase was further diminished when it became known that lesions other than prostatic carcinoma could elevate the serum level of this enzyme (Woodward, 1959). Furthermore, many sources of error in the estimation of serum acid phosphatase came to light (Ozar, Isaac and Volk, 1955). In spite of these limitations, this enzyme has remained a useful aid in the diagnosis and follow-up of prostatic cancer.

Throughout the years, however, numerous surgical textbooks and medical teachers have continued to teach that rectal examination can so increase serum acid phosphatase levels as to induce a false positive diagnosis of carcinoma of the prostate. The purpose of this study was to evaluate, under controlled conditions, the effect of rectal examination of enlarged benign or malignant prostates on serum acid phosphatase levels.

\section{Subjects and methods}

Seventy-eight patients attending the Urology Clinic of the Lagos University Teaching Hospital were admitted into the study. Thirty-nine patients (50\%) had benign prostatic hypertrophy, $22(28 \%)$ had carcinoma of the prostate whilst $17(22 \%)$ patients with no urinary lesions served as controls. The mean ages of the three groups were 68,69 and 60 years respectively. No rectal examination was done on any of the patients in the preceding $48 \mathrm{hr}$.

After a general physical examination, rectal examination was carried out in the left lateral position and palpation of the prostate was continued for $2 \mathrm{~min}$. Twenty millilitres of blood were collected from each patient (a) $5 \mathrm{~min}$ before, (b) $15 \mathrm{~min}$ after and (c) $24 \mathrm{hr}$ after rectal examination.

Total serum acid phosphatase (TSP) and tartrateinhibited, prostatic acid phosphatase (PF) were determined in all patients (King and Jagatheesan, 1959). Blood was collected into sterile universal bottles with extreme care to prevent haemolysis. Questionable samples were excluded from analysis. After centrifugation, serum was collected and acid phosphatase estimated immediately. All determinations were done in duplicate by the same investigator and the mean of two values was recorded. 
TABLE I. TSP and PF before and after rectal examination in controls, benign prostatic hypertrophy (BPH) and carcinoma of prostate

\begin{tabular}{|c|c|c|c|c|}
\hline & & $\begin{array}{l}5 \text { Minutes before } \\
\text { rectal examination } \\
(\mathrm{KAU} / \mathrm{dl})\end{array}$ & $\begin{array}{l}15 \text { Minutes after } \\
\text { rectal examination } \\
(\mathrm{KAU} / \mathrm{dl})\end{array}$ & $\begin{array}{l}24 \text { Hours after } \\
\text { rectal examination } \\
(\mathrm{KAU} / \mathrm{dl})\end{array}$ \\
\hline \multicolumn{5}{|c|}{ Controls $n=17$} \\
\hline \multirow[t]{3}{*}{ TSP } & Range & $0 \cdot 2-2 \cdot 0$ & $0 \cdot 4-2 \cdot 4$ & $0 \cdot 2-2 \cdot 4$ \\
\hline & Mean & $1 \cdot 11$ & 1.21 & 1.03 \\
\hline & \pm s.d. & 0.90 & 0.78 & 0.89 \\
\hline \multirow[t]{3}{*}{ PF } & Range & $0 \cdot 0-0 \cdot 5$ & $0 \cdot 0-0 \cdot 3$ & $0.0-0.5$ \\
\hline & Mean & $0 \cdot 14$ & 0.19 & $0 \cdot 15$ \\
\hline & \pm s.d. & $0 \cdot 12$ & $0 \cdot 14$ & $0 \cdot 14$ \\
\hline \multicolumn{5}{|c|}{ BPH $n=39$} \\
\hline \multirow[t]{3}{*}{ TSP } & Range & $0 \cdot 2-2 \cdot 1$ & $0 \cdot 4-2 \cdot 4$ & $0 \cdot 2-2 \cdot 1$ \\
\hline & Mean & 1.42 & 1.40 & $1 \cdot 17$ \\
\hline & \pm s.d. & $0 \cdot 70$ & 0.69 & 0.70 \\
\hline \multirow[t]{3}{*}{ PF } & Range & $0.0-0.9$ & $0 \cdot 0-0 \cdot 7$ & $0.0-0.7$ \\
\hline & Mean & 0.40 & 0.42 & $0 \cdot 35$ \\
\hline & \pm s.d. & $0 \cdot 28$ & 0.26 & $0 \cdot 29$ \\
\hline \multicolumn{5}{|c|}{ Carcinoma of prostate $n=22$} \\
\hline \multirow[t]{3}{*}{ TSP } & Range & $1 \cdot 0-19 \cdot 6$ & $0.4-35.0$ & $0 \cdot 8-16.0$ \\
\hline & Mean & $6 \cdot 7$ & $10 \cdot 8$ & $6 \cdot 6$ \\
\hline & \pm s.d. & $5 \cdot 2$ & $11 \cdot 1$ & $5 \cdot 0$ \\
\hline \multirow[t]{3}{*}{ PF } & Range & $0 \cdot 4-14 \cdot 2$ & $0 \cdot 3-32 \cdot 5$ & $0.4-14.8$ \\
\hline & Mean & 5.1 & 8.5 & 4.9 \\
\hline & \pm s.d. & 4.5 & 9.9 & 4.3 \\
\hline
\end{tabular}

Diagnoses were confirmed in all cases by histology. TSP and PF above 3 and $1 \mathrm{KAU} / \mathrm{dl}$ respectively were considered elevated.

\section{Results}

The results of TSP and PF determinations for all three groups are summarized in the Table. There was no elevation of acid phosphatase in the control group after rectal examination. In the group with benign prostatic hypertrophy both the TSP and PF also remained the same before and after rectal examination. The cancer patients included six men who had previously been treated by orchidectomy and/or hormone therapy. At the time of the study two of them had exacerbation of their disease with extensive osseous metastases in spite of continued hormone therapy while the other four were in complete remission. Sixteen patients were untreated. As a group rectal examination produced a transient rise in the enzyme level (though statistically insignificant, $P>0 \cdot 1)$. This elevation, however, occurred in two patients who had become refractory to treatment and in five untreated patients with advanced disease. In all patients who were in remission and in $68.8 \%$ of untreated patients, rectal examination produced no change in TSP and PF levels.

It is important to emphasize that this rise in acid phosphatase when it occurred could not have caused any misdiagnosis nor problem in monitoring the effect of therapy because the resting enzyme levels $\delta$ were already diagnostically elevated.

\section{Discussion}

The evidence for the generally held belief that rectal examination causes misleading elevation of serum acid phosphatase is largely provided by the reports of Hock and Tessier (1949), Daniel and Vanzyl (1952), Bonner et al. (1954) and Glenn and Spanel (1959). The study of Daniel and Vanzyl (1952) showed that in only $9.7 \%$ of the patients did rectal examination produce elevated acid phosphatase. It is now, however, recognized that the range of false positive acid phosphatase in patients with benign prostate without rectal examination is of the order of 10\% (Ozar et al., 1955). Bonner, Homburger and Fishman (1954) reported elevated acid phosphatase in 12 of 22 patients studied; their charts, however, showed that except in one patient the TSP levels were not above normal values. The abnormal elevations occurred in PF only. Even here, only $13.6 \%$ had PF levels above $1 \mathrm{KAU} / \mathrm{dl}$. Elevation of $\mathrm{PF}$ in the presence of normal TSP was not seen in the current series and has been denied by many authors (Whitmore et al., 1956).

Glenn and Spanel (1959) studied oniy 12 patients, of whom three had pre-rectal examination TSP levels above normal. One of these was found to have carcinoma of the prostate. Of the remaining nine, only two showed elevated TSP following massage. 
The number of cases upon which their conclusions were based was too small in our view.

Rectal examination did not produce any significant elevation of either TSP or PF in both control patients and those with benign prostatic enlargement in our study. This agrees with recent reports (Wiederhorn and Pickens (1973), Greene and Thompson (1974), Khan et al. (1978), Steele (1979) and Daar et al. (1981)). The response of the patients with carcinoma of the prostate showed three patterns:

1. Treated patients who were in remission with low resting acid phosphatase responded to rectal examination as those with benign prostates. This finding agrees with the observation of Kendal (1961).

2 . In patients who no longer appeared to respond to hormonal therapy with high resting enzyme levels, rectal examination produced further rise.

3. Amongst the untreated patients rectal examination caused a rise in the enzyme levels in some and produced no change in others. Thus in the cancer group, the elevation produced by rectal examination rather than mislead strengthened the suspicion of malignancy.

Kendal (1961) offered a plausible explanation for this state of affairs. Prostate acid phosphatase is normally an exocrine secretion and drains through the ducts into the posterior urethra. Prostatic massage merely milks the acid phosphatase through the ducts into the posterior urethra and not into the circulation and this explains why the serum level remains normal in controls and benign prostates. Early or localized lesions with no ductal occlusion behave like benign glands. Advanced cancer of the prostate and those refractory to therapy invade and occlude the ductal systems with intravasation of the enzyme into the general circulation; prostatic massage of such glands produces further intravasation of acid phosphatase.

The poor sensitivity of standard enzymatic methods has been blamed by some of the earlier authors for the failure to record a rise in enzyme levels after rectal examination. The use of radioimmunoassay in the estimation of prostatic acid phosphatase has therefore attracted much attention in the past few years because of the claim of better sensitivity and specificity than the enzymatic methods (Foti et al., 1977). More recent reports have, however, questioned this claim (Quinones et al., 1981; Sarosdy, Kledzik and Lamn, 1982).

Until unequivocal proofs of the superiority of radioimmunoassay over standard enzymatic techniques are available we should not discard the latter which are within the reach of most medical communities.

\section{Conclusion}

From the results of this study and the review of the literature, we conclude that rectal examination, contrary to still popular belief (Daar et al., 1981), does not invalidate the usefulness of acid phosphatase as an ancillary aid in the diagnosis of cancer of the prostate. When properly estimated with care taken to eliminate sources of errors, an abnormal level of acid phosphatase should always arouse the suspicion of a malignant prostate or other lesion associated with high acid phosphatase whether estimated before or after rectal examination. Because of the multiple sources of error, even in centres where acid phosphatase is determined by radioimmunoassay, the definitive diagnosis of cancer of the prostate must still be by histology.

\section{Acknowledgments}

We are grateful to Mrs O. O. Sanu and Mr J. B. Ojo for their technical assistance and to Mr F. N. Emebo for secretarial help.

\section{References}

Bonner, C.D., Homburger, F. \& Fishman, W.H. (1954) Some factors other than neoplasma altering the prostatic fraction of acid phosphatase in the serum. Surgery, Gynecology and Obstetrics, 99, 179.

DaAr, A.S., Merrill, C.R., Moolla, S.M. \& Clarke, T.N.S. (1981) Rectal examination and acid phosphatase: evidence for persistence of a myth. British Medical Journal, 282, 1378.

DANIEL, O. \& VANZYL, J.S. (1952) Rise of serum acid phosphatase level following palpation of prostate. Lancet, $\mathbf{i}, 998$.

Foti, A.G., COOPER, J.F., HerSChMAN, H. \& MalvaeZ, R.R. (1977) Detection of prostatic cancer by solid-phase radioimmunoassay of the serum prostatic acid phosphatase. New England Journal of Medicine, 297, 1357.

GLENN, J.F. \& SPANEL, D.L. (1959) Serum acid phosphatase and the effect on prostatic massage. Journal of Urology, 82, 240.

GrEeNE, F.T. \& THOMPSON, I.M. (1974) The effects of various manipulations on serum phosphatase levels in benign disease. Journal of Urology, 112, 232.

Gutman, E.B. \& Gutman, A.B. (1938) An 'acid' phosphatase occurring in the serum of patients with metastasizing carcinoma of the prostate gland. Journal of Clinical Investigation, 17, 473.

Hock, E. \& TESSIER, R.N. (1949) Elevation of serum acid phosphatase following prostatic massage. Journal of Urology, 62, 488.

KENDAL, A.N. (1961) Acid phosphatase elevation following prostatic examination in the early diagnosis of prostatic carcinoma. Journal of Urology, 86, 442.

KhaN, A.N., LEE, G.S., JACKetT, M.R., NewCombe, R.G. \& PATHY, N.S. (1978) The effect of routine digital examination on the prostate on serum acid phosphatase. British Journal of Urology, 50, 182.

KING, E.J. \& JeGatheeSAN, K. (1959) A method for the determination of tartrate-Labile, prostatic acid phosphatase in serum. Journal of Clinical Pathology, 12, 85.

Kutscher, W. \& Wolbergs, H. (1935) Prostatic acid phosphatase. Zeitschrift für physiologische Chemie, 236, 3237. Quoted by Kendal, A.R. (1961).

OZAR, M.B., IsAaC, C.A. \& VALK, W.L. (1955) Methods for elimination of errors in serum acid phosphatase determinations. Journal of Urology, 74, 150.

Quinones, G., RoHner, T.J. JR, Demers, L.M. \& Drago, J.H. (1981) Will prostatic acid phosphatase determination by RIA increase the diagnosis of early prostate cancer? Journal of Urology, 125, 361 .

Sarosdy, M.F., Kledzik, G. \& Lamn, D. (1982) Serum and bone 
marrow radioimmunoassay of acid phosphatase in prostatic cancer. Urology, XIX, 33.

STEELE, R.J.C. (1979) The effects of rectal examination on serum acid phosphatase. Journal of the Royal College of Surgeons of Edinburgh, 24, 227.

WIEDERHORN, A.R. \& Pickens, R.L. (1973) Serum acid phosphatase levels following prostatic massage: A re-evaluation. Journal of Urology, 109, 855.
WhitMORE, W.F. JR, BodansKy, O., SCHWARTZ, M.K., YING, S.H. \& DAY, E. (1956) Serum prostatic acid phosphatase levels in proved cases of carcinoma or benign hypertrophy of prostate. Cancer (Philadelphia), 9, 228.

WoODWARD, H.Q. (1952) Factors leading to elevation in serum acid glycerophosphatase. Cancer (Philadelphia), 5, 236.

WOODWARD, H.Q. (1959) The clinical significance of serum acid phosphatase. American Journal of Medicine, 27, 902. 